\title{
Classification of Calligraphy Writing Types Using Convolutional Neural Network Method (CNN)
}

\section{Klasifikasi Jenis Tulisan Kaligrafi Menggunakan Metode Convolutional Neural Network (CNN)}

\author{
Oddy Virgantara Putra ${ }^{1}$, Aziz Musthafa ${ }^{2}$, Muhammad Nur ${ }^{3}$, Muhamad Rido ${ }^{4}$ \\ \{oddy@unida.gontor.ac.id ${ }^{1}$, aziz@unida.gontor.ac.id ${ }^{2}$, mnur@unida.gontor.ac.id ${ }^{3}$, muhamad.rido@mhs.unida.gontor.ac.id ${ }^{4}$ \}
}

Program Studi Teknik Informatika, Fakultas Sains dan Teknologi, Universitas Darussalam Gontor, Ponorogo

\begin{abstract}
Calligraphy is the art of beautiful Arabic writing in which a series of letters are formed in appropriate proportions, maintaining distance and accuracy containing verses from the Qur'an or Hadith. There is a challenge to recognize the type of calligraphy using machine learning. This study aims to classify the types of calligraphy writing for ordinary people who do not understand the differences between each type of calligraphy writing. This study builds a model using the Convolutional Neural Network (CNN) method. The image used will go through a noise cleaning, resizing, and cropping process. This method is to carry out the process of classifying the type of calligraphy using a dataset consisting of 230 of 2 different types of calligraphy, namely the Naskhi and Riq'ah types. $80 \%$ is used as training data and $20 \%$ for test data. In the modeling process there are two convolutional layers and two MaxPooling layers followed by a Fully connected layer. The CNN modeling results used to test the built data have an average percentage result of $89 \%$ accuracy from the training data used. For further research, it can be developed with other types of calligraphy.
\end{abstract}

Keywords - Calligraphy; Classification; Convolutional Neural Network; Khatt.

Abstrak- Kaligrafi adalah ilmu seni menulis Arab dengan indah dimana serangkaian huruf dibentuk dalam proporsi yang sesuai, menjaga jarak dan akurasi yang berisi ayat-ayat dari Al-Qur'an atau Hadits. Ada tantangan untuk mengenali jenis kaligrafi menggunakan machine learning. Penelitian ini bertujuan untuk menklasifikasi jenis tulisan kaligrafi bagi orang awam yang belum mengerti perbedaan setiap jenis dari tulisan kaligrafi. Penelitian ini membangun sebuah model menggunakan metode Convolutional Neural Network (CNN). Citra yang digunakan akan melalui proses pembersihan noise, resizing, dan cropping. Metode ini untuk melakukan proses klasifikasi jenis tulisan kaligrafi menggunakan dataset yang terdiri dari 230 dari 2 jenis kaligrafi yang berbeda, yaitu jenis Naskhi dan Riq'ah. $80 \%$ digunakan sebagai data latih dan $20 \%$ untuk data tesnya. Dalam proses pemodelan terdapat dua convolutional layers dan dua MaxPooling layers yang diikuti dengan Fully connected layer. Hasil pemodelan CNN yang digunakan untuk menguji data yang dibangun memiliki hasil persentase rata-rata accuracy $89 \%$ dari data latih yang digunakan. Untuk penelitian selanjutnya bisa dikembangkan dengan jenis kaligrafi yang lain.

Kata Kunci - Kaligrafi; Klasifikasi; Convolutional Neural Network; Khat.

\section{PENDAHULUAN}

Kaligrafi merupakan seni tulis Islam yang indah dalam Bahasa Arab yang merupakan keterampilan tangan dengan dipadukan rasa seni yang terkandung dalam hati penulisnya. Dibandingkan dengan seni Islam lain, kaligrafi ini mempunyai merupakan ekpresi spirit Islam[1]. Permasalahannya dalam dunia klasifikasi jenis tulisan kaligrafi ini meliputi serangkaian huruf yang dibentuk, penjagaan jarak dan akurasi tulisan yang dimana kaligrafi ini berisi ayatayat Al-Qur'an dan Hadits. Dalam pengenalan jenis kaligrafi ini masih banyak orang yang belum bisa membedakan setiap jenis dari kaligrafi. Di Gontor Ponorogo Jawa Timur masih sedikit dari lingkungan santri yang belum bisa mengajarkan penulisan tentang kaligrafi yang sesuai sanad. Dan sedikit dari peminat yang mau belajar dan memahami karena memiliki tingkat kesulitan yang berbeda-beda.

Untuk menentukan jenis kaligrafi yang ada, maka diperlukan suatu klasifikasi kaligrafi berdasarkan keindahan disetiap tulisan kaligrafi tersebut. Salah satu metode yang digunakan dalam pengklassifikasiannya adalah dengan menggunakan metode Convolutional Neural Networks (CNN). CNN merupakan pengembangan dari Multilayer Percepton $(M L P)$ yang didesain untuk mengolah data citra dua dimensi. CNN ini terdiri dari satu atau lebih lapisan convolutional, yang dimana suatu lapisan sub-sampling yang diikuti oleh satu atau lebih lapisan yang saling terhubung penuh sebagai standar jaringan syaraf. Setiap citra yang digunakan akan melewati beberapa proses seperti convolutional layer, pooling yang digunakan untuk pengekstrasian fitur dari citra, dan proses terakhir adalah dengan fully connected layer untuk menyelesaikan pengklasifikasian. Sehingga algoritma CCN yang digunakan untuk pengolahan citra bisa dibilang cukup efektif[2][3]. 
Beberapa penelitian yang terkait dalam pengklasifikasian jenis tulisan kaligrafi yang telah dilakukan seperti Arabic handwriting recognition system using convolutional neural network. Klasifikasi dilakukan dalam penelitian ini menggunakan dataset tulisan tangan dengan gambar bitmap Red Green Blue (RGB) yang menjadi sumber data yang unik. Peneliti akan melakukan pengenalan pola tulisan menggunakan dataset Arabic Handwriting Character Dataset (AHCD). Selanjutnya peneliti akan melakukan proses MLP yang dilatih dengan algoritma back propagation dan CNN. Hasil percobaan yang dilakukan menunjukan bahwa model mendapatkan hasil persentase mecapai nilai ratarata yang cukup baik dengan accuracy $94,93 \%$ dan $88 \%$ pada dataset AHCD[4].

Penelitian berikutnya juga melakukan klasifikasi tanaman pada citra dengan menggunakan metode CNN. Data yang digunakan pada penelitian ini adalah data tanaman kelapa, pisang, padi, cabai dan bawang merah. Data tersebut terdiri dari 500 gambar. Dalam penerapa metode CNN dalam membangun model, peneliti menggunakan lima convolutional layers, tiga max pooling layers dan tiga fully connected layers. Dengan hasil rata-rata akurasi $100 \%$ pada tahap training, 93\% data validasi, dan $82 \%$ data tes. Dalam penelitian ini menunjukan bahwa metode CNN mempunyai potensi untuk pengenalan objek dalam membedakan jenis tanaman yang bisa menjadi pertimbangan dalam menentukan objek pada citra[5].

Dalam penelitian lain [6] penggunaan metode CNN untuk pengenalan pola tulisan arab. Peneliti menggunakan model CNN dengan tiga convolutional layers yang disetiap layer memiliki 128 filter, dengan ukuran kernel 5x5, dan 1HL dimana setiap layer memiliki neuron sebanyak 128, ukuran citra yang digunakan 64x64. Kemudian dinormalisasikan menggunakan fungsi aktivasi ReLU dan satu dimensi citra (grayscale). Dengan perbandingan data training dan datates yang digunakan adalah 70:30. Dataset yang digunakan untuk klasifikasi pada citra yaitu 25200 data dengan hasil presisi $71,44 \%$, dan recall $69,18 \%$. Dengan hasil rata-rata accuracy $78,10 \%$.

Dalam penelitian ini akan berfokus pada penerapan metode CNN dalam membangun model untuk melakukan klasifikasi jenis tulisan kaligrafi. Adapun jenis kaligrafi yang akan di klasifikasi pada penelitian ini ada dua jenis kaligrafi yaitu khat naskhi dan khat riq'ah.

\section{METODE}

Tujuan utama dari penelitian ini adalah untuk membangun model klasifikasi pada jenis tulisan kaligrafi menggunakan metode $\mathrm{CNN}$, metode ini cukup efektif untuk pengolahan citra karena dapat melakukan proses pengenalan pola pada fitur-fitur citra[7]. Tahapan-tahapan dalam menggunakan metode CNN sebagai berikut:

\section{A. Tahapan pengumpulan data}

Pada tahapan ini dilakukan pengumpulan data dengan observasi langsung oleh peneliti, yang dimana peneliti bekerjasama dengan mahasiswa Universitas Darussalam Gontor yang menuliskan kaligrafi dimana mahasiswa tersebut sudah mendapatkan sanad penulisan kaligrafi. Dataset ini memiliki dua jenis tulisan kaligrafi dengan jumlah untuk data training naskhi 105 kata dan riq'ah 90 kata. Sedangkan dataset untuk test naskhi dan riq'ah adalah 20 kata perejenis. Setiap jenis tuisan kaligrafi memiliki perbedaan pola dan bentuk yang khas. Adapun dari data yang didapat adalah data-data yang akan di olah dan diproses pada penelitian ini. seperti yang ditampilkan pada Gambar 1.

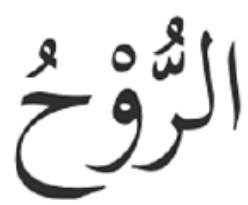

(a)

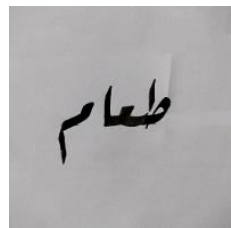

(b)

Gambar 1. (a) Naskhi, (b) Riq'ah

\section{B. Tahapan pre-processing}

Pada bagian pre-processing dilakukan untuk mendapatkan hasil akurasi yang maksimal dalam pengolahan data awal. Pada tahapan ini terdapat dua tahapan yang pertama adalah pembersihan noise. Pembersihan noise ini dilakukan untunk meningkatkan kualitas gambar sehingga nantinya akan menghasilkan nilai akurasi yang tinggi.

Proses selanjutnya adalah cropping. Cropping ini dilakukan untuk menghilangkan area terluar yang tidak diinginkan dari gambar. Proses ini terdiri dari penghapusan beberapa area untuk menghilankan sampah asing dan meningkatkan pembingkaiannya serta mengubah rasio pada objek[8].

Proses kedua adalah resizing image pada data citra. Resizing image adalah proses mengubah ukuran dimensi suatu citra menjadi lebih besar atau kecil dari sebelumnya. Dari data citra yang telah didapatkan, akan dilakukan resizing 
Procedia of Engineering and Life Science Vol. 2. No. 1 October 2021

Seminar Nasional \& Call Paper Fakultas Sains dan Teknologi (SENASAINS $3^{\text {rd) }}$

Universitas Muhammadiyah Sidoarjo

image menjadi 256 x 256 pixel, seperti yang ditampilkan pada gambar 2.

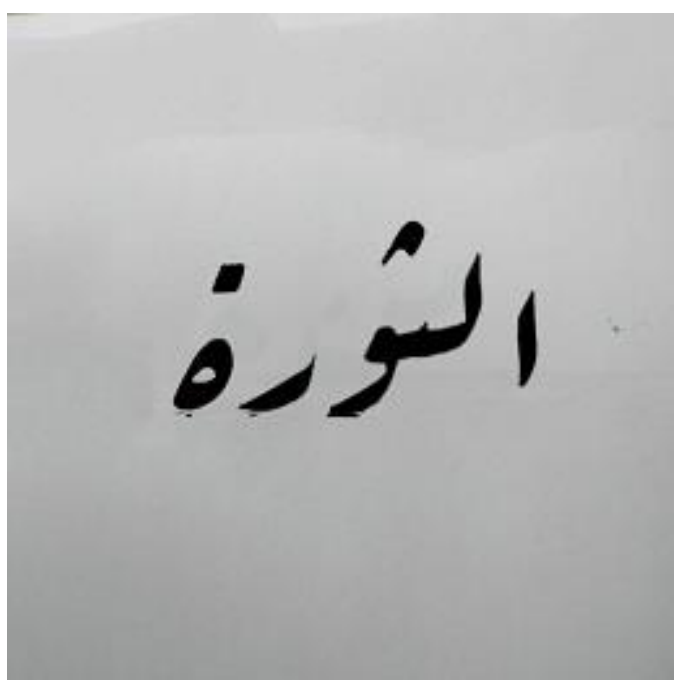

( a )

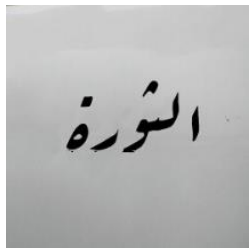

( b )

Gambar 2. (a) Citra dengan ukuran asli. (b) Citra hasil resizing

\section{Rancangan arsitektur cnn}
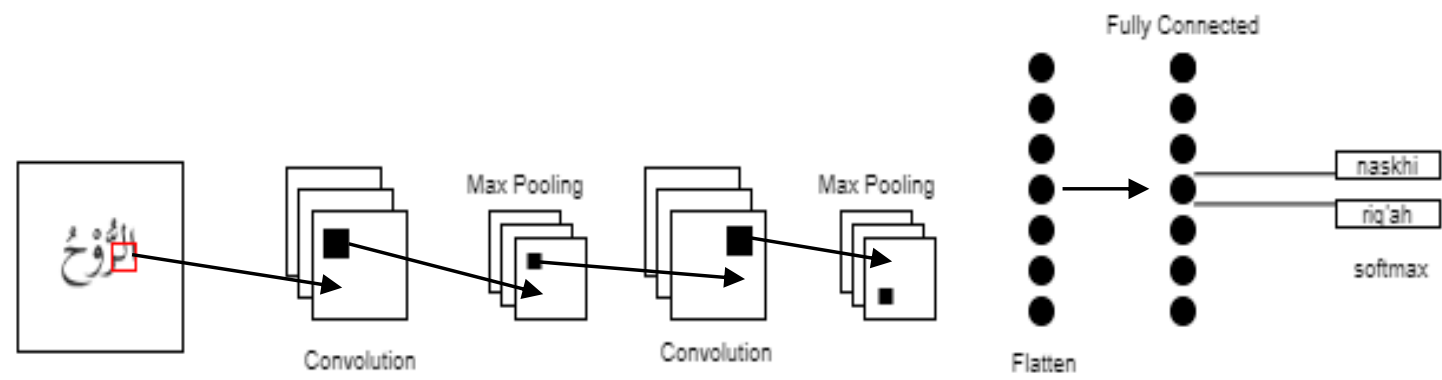

Gambar 3. Rancangan aristektur CNN

Tahap convolutional layers sampai tahap fully connected layer dilakukan perkalian matriks yang diikuti dengan sebanyak 32 bias offset dan tahap terakhir pada softmax yang menjadi hasil output sebanyak 1 node yang akan mengashilkan bentuk neuron yang saling terhubung kepada objek yang telah diberikan label. Hasil data yang telah dilatih akan disimpan dalam model yang dapat digunakan untuk pengujian. Selanjutnya melakukan pelatihan menggunakan max pooling pada pooling layer. Untuk tahap-tahap pelatihannya dapat di lihat pada gambar 4. 
Procedia of Engineering and Life Science Vol. 2. No. 1 October 2021

Seminar Nasional \& Call Paper Fakultas Sains dan Teknologi (SENASAINS 3rd)

Universitas Muhammadiyah Sidoarjo

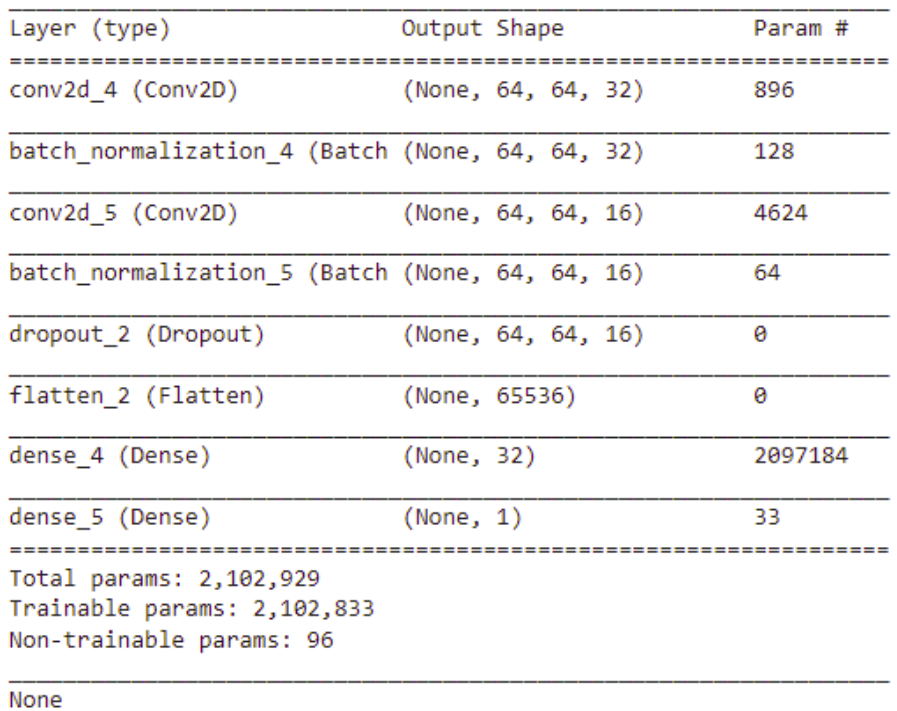

Gambar 4. Ringkasan dari arsitektur CNN

Penelitian ini menggunakan metode CNN dalam membangun model yang akan dipakai untuk melakukan klasifikasi jenis tulisan kaligrafi. Data yang didapat akan dibagi menjadi beberapa kelas yang berbeda sesuai dengan jenis kaligrafi yang melewati proses splitting data sehingga keseimbangan data yang ada pada setiap kelas dapat diterapkan. Dalam rancangan arsitektur yang akan dilakukan peneliti menerapkan dua Convolutional Layers dan dua Max Pooling Layers dalam proses ekstraksi fitur untuk menghasilkan feature map. Pada setiap bagian Convolutional Layers dalam melakukan filter dengan menggunakan dimensi $3 \times 3$ dan max pooling layers dengan dimensi $2 \times 2$. Citra akan melalui proses flatten bertujuan untuk mengubah feature map yang masih berbentuk multidimensial array menjadi sebuah vector agar dapat digunakan sebagai input dari fully connected layer yang berfungsi untuk mengolah data sehingga dapat diklasifikasikan. Fully connected layer digunakan untuk melakukan transformasi pada dimensi sebuah data agar data dapat diklasifikasikan secara linear[5]. Rancangan arsitektur CCN dalam membangun model dapat dilihat pada gambar 4 .

\section{HASIL DAN PEMBAHASAN}

Sebelum melakukan penelitian, data yang berjumlah 240 kata dibagi menjadi 2 yaitu sebagai data tain dan data test, dimana peneliti membagi dengan skala 80 x 20 secara random. Sehingga data train berjumlah 210 kata dan data tes berjumlah 40 kata. Adapun hasil pengujian yang telah dilakukan dengan menerapkan algoritma Convolutional Neural Network sebagai berikut :

\section{A. Hasil penelitian}

Proses pemodelan CNN yang dilakukan dalam penelitian ini telah dilakukan menggunakan Google Collaboratory dan Kaggle dengan menggunaka akses GPU yang telah disesuaikan. Dengan mengimplementasikan arsitektur CNN yang telah dirancang. Dalam proses pembelajaran metode Algoritma CNN memanfaatkan proses konvolusi dengan menggunkan sebuah kernel konvolusi dengan ukuran tertentu ke sebuah gambar.

Pengujian yang dilakukan dengan menggunakan nilai rate 8 epoch pada data latih dan data validasi. Pada proses pelatihan model menghasilkan nilai accuracy dan nilai loss yang dapat dilihat pada gamar 5 dan 6 . 
Procedia of Engineering and Life Science Vol. 2. No. 1 October 2021

Seminar Nasional \& Call Paper Fakultas Sains dan Teknologi (SENASAINS 3 ${ }^{\text {rd }}$ )

Universitas Muhammadiyah Sidoarjo

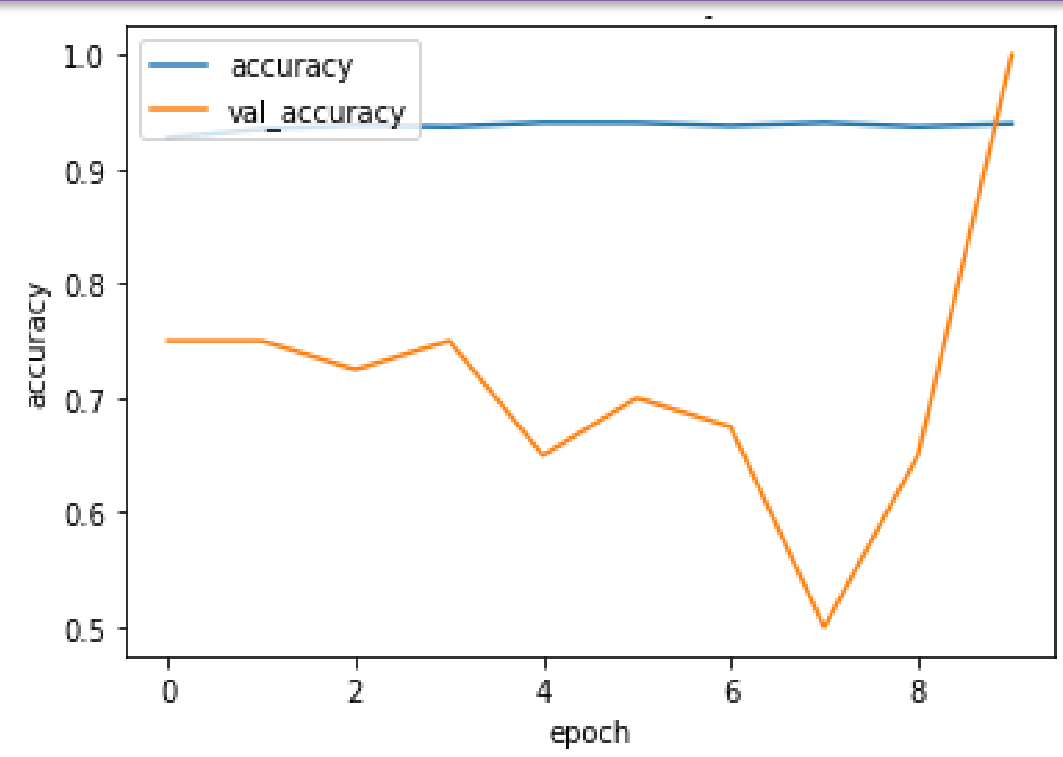

Gambar 5. Hasil nilai akurasi dari proses pelatihan pada data train dan data validasi

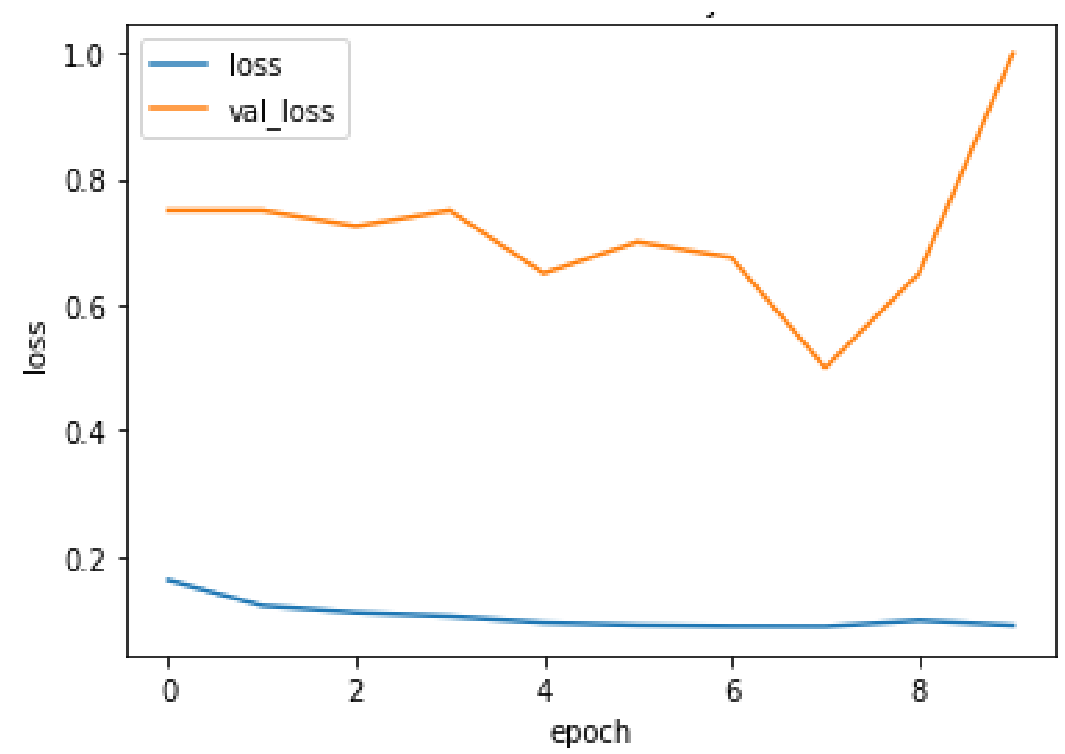

Gambar 6. Hasil nilai loss dari proses pelatihan pada data train dan data validasi

Pada gambar 5 dan 6 yang menyatakan bahwa hasil persentase pengujian Algoritma CNN yaitu dengan rata-rata accuracy $89 \%$ pada data train dan rata-rata accuracy $75 \%$ pada data validasi. Hasil dari pengujian yang dilakukan bahwa jumlah data dan layer pada arsitektur CNN dapat mempengaruhi hasil akurasi pada pengujian data. Model yang dibangun akan diimplementasikan untuk mengklasfikasi jenis tulisan kaligrafi pada 40 data test. Hasil klasifikasi pada data test yang dilakukan terhadapa dua jenis kaligarafi dapat dilihat pada gambar 5 . 
Procedia of Engineering and Life Science Vol. 2. No. 1 October 2021

Seminar Nasional \& Call Paper Fakultas Sains dan Teknologi (SENASAINS 3 ${ }^{\text {rd }}$ )

Universitas Muhammadiyah Sidoarjo
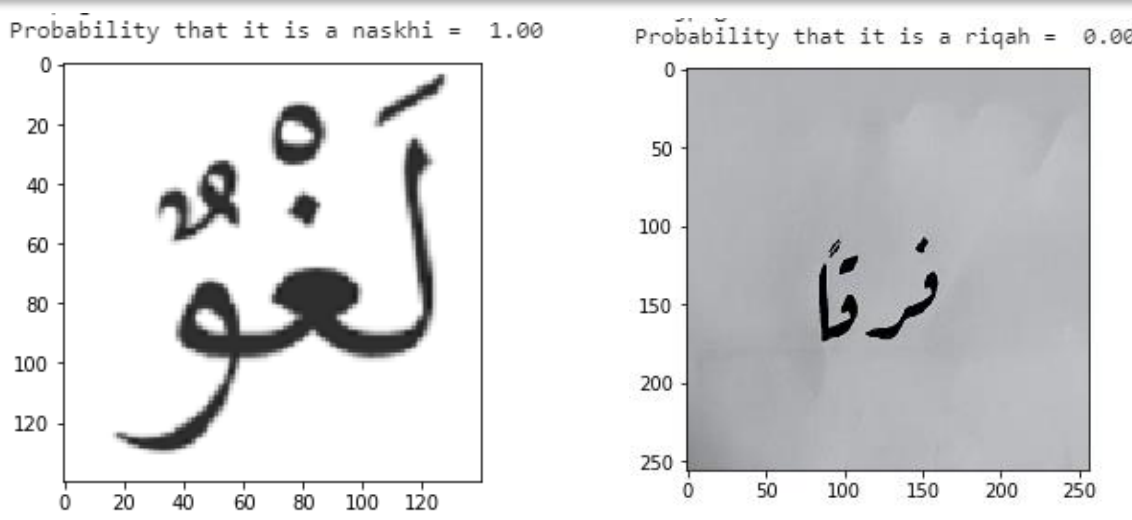

Gambar 7. Hasil implementasi model pada data test

Berdasarkan hasil akurasi yang didapatkan dari pengujian algoritma CNN, dapat disimpulkan bahwa penelitian ini dengan dua jenis data tulisan kaligrafi yang berbeda dapat diklasifikasi menggunakan algoritma CNN yang diterapkan dapat untuk membedakan jenis tulisan kaligrafi yang berbeda.

\section{KESIMPULAN}

Klasifikasi jenis tulisan kaligrafi dengan menggunakan metode Convolutional Neural Network (CNN) menghasilkan akurasi yang cukup baik. Dengan memperoleh rata-rata accuracy mencapai $89 \%$ pada data train dan $75 \%$ pada data validasi. Berdasarkan hasil tingkat akurasi yang didapat di simpulkan bahwa penggunaan arsitetur yang diterapkan dapat mempengaruhi tingkat keakurasian pada data yang digunakan. CNN dapat memberikakan hasil klasifikasi yang cukup baik dalam melakukan proses pengenalan objek dan klasifikasi jenis tulisan kaligrafi. Hasil implemetasi metode CNN untuk klasifikasi jenis tulisan kaligtrafi menunjukan bahwa arsitektur CNN dapat mengklasifikasi dua jenis secara otomastis dengan memberikan label pada data. Sehingga dapat membantu orang yang belum mengetahui jenis tulisan kaligrafi.

\section{UCAPAN TERIMAKASIH}

Terima kasih kepada Program Studi Teknik Informatika Universitas Darussalam Gontor dan kepada para dosen pembimbing yang telah membingbing saya dalam menyelesaikan penelitian ini. Penelitian ini didukung oleh pihak Markaz pusat Kaligrafi Universitas Darussalam Gontor Ponorgo, Indonesia.

\section{REFERENSI}

[1] H. Makmur and Y. Abdullah, "Manifestasi khat naskhi sebagai tulisan asas Al-Quran: Kajian terhadap jenis khat naskhi sebagai tulisan asas Al- Quran mushaf uthmani," no. January, 2011, [Online]. Available: https://www.researchgate.net/publication/282913527\%0AMANIFESTASI.

[2] M. R. Alwanda, R. P. K. Ramadhan, and D. Alamsyah, "Implementasi Metode Convolutional Neural Network Menggunakan Arsitektur LeNet-5 untuk Pengenalan Doodle," J. Algoritm., vol. 1, no. 1, pp. 45-56, 2020, doi: 10.35957/algoritme.v1i1.434.

[3] D. Li et al., "A recognition method for rice plant diseases and pests video detection based on deep convolutional neural network," Sensors (Switzerland), vol. 20, no. 3, 2020, doi: 10.3390/s20030578.

[4] N. Altwaijry and I. Al-Turaiki, "Arabic handwriting recognition system using convolutional neural network," Neural Comput. Appl., vol. 33, no. 7, pp. 2249-2261, 2021, doi: 10.1007/s00521-020-05070-8.

[5] E. N. Arrofiqoh and Harintaka, "IMPLEMENTASI METODE CONVOLUTIONAL NEURAL NETWORK UNTUK KLASIFIKASI TANAMAN PADA CITRA RESOLUSI TINGGI ( The Implementation of Convolutional Neural Network Method for Agricultural Plant Classification in High Resolution Imagery )," Geomatika, vol. 24, no. 2, pp. 61-68, 2018.

[6] N. Kasim and G. S. Nugraha, "Pengenalan Pola Tulisan Tangan Aksara Arab Menggunakan Metode Convolution Neural Network," J. Teknol. Informasi, Komputer, dan Apl. (JTIKA ), vol. 3, no. 1, pp. 85-95, 2021, doi: 10.29303/jtika.v3i1.136.

[7] Sam'ani and M. H. Qamaruzzaman, "Pengenalan Huruf Dan Angka Tulisan Tangan Mengunakan Metode 
Procedia of Engineering and Life Science Vol. 2. No. 1 October 2021

Seminar Nasional \& Call Paper Fakultas Sains dan Teknologi (SENASAINS 3rd)

Universitas Muhammadiyah Sidoarjo

Convolution Neural Network ( CNN )," J. Speed - Sentra Penelit. Eng. dan Edukasi, vol. 9, no. 2, pp. 55-64, 2017.

[8] E. S. Udkhiati Mawaddah, Hendrawan Armanto, "Prediksi Karakteristik Personal Menggunakan Analisis Tanda Tangan Dengan Mengggunakan Metode Convolutional Neural Network (CNN)," J. Ilm. Tek. Inform., vol. 15, no. 1, pp. 123-133, 2021. 